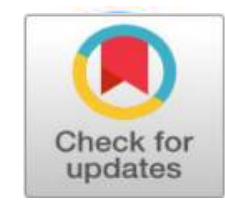

PRIMARY RESEARCH

\title{
Leadership is skin deep: A new way of being through inside-out effect of leadership and its strategies in teaching
}

\author{
Shirzad Mansouri ${ }^{1,}{ }^{*}$, Nathara Mhunpiew ${ }^{2}$ \\ ${ }^{1,2}$ Assumption University of Thailand, Bangkok, Thailand
}

\section{Keywords: \\ Self \\ Self-development \\ Self-leadership \\ Inside-Out effect \\ Leader}

Received: 26 March 2016

Accepted: 30 March 2016

Published: 21 June 2016

\begin{abstract}
The current review study aims to explore the concept of self and its role in selfleadership and propose strategies for teacher leaders in enhancing their awareness of personal qualities in leading their classrooms. This inside-out effect of self and selfdevelopment can be the key to success for the leader to pave the way for more sustainable development in the organization and its components. The inside-out effect is a transformational change within a leader and reflects the beauty inside the world outside by creating a relationship in his leadership. The main goal of the current paper is to review the way this internal process occurs and manifests in a whole person called a leader from different theoretical perspectives. The current study is a review paper that reviews and analyzes existing scholarly work and literature on leadership and its effectiveness. Based on the review, implications for the teachers and principals are discussed.
\end{abstract}

(C) 2016 The Author(s). Published by TAF Publishing.

\section{INTRODUCTION}

Various organizations, either in business or education, have followers, employers and students who admire their leaders for having certain qualities which have been the origin of change first in the leader and next in the organization. These qualities are necessary for the leader to be an authentic leader. It is believed that first for a leader is to understand himself, because the hardest person he will ever have to lead is himself (Murray, 2015). Bill George in his recent interview with Fortune believed that the hierarchical leader is out. The empowering leader is in. This means when he has a deep understanding of his authentic SELF, he will find that leading is much easier. Moreover, Cashman (2012) also emphasized that we tend to see leadership as an external event but leadership is not simply something we do. The definition of leadership usually is dealing with outer manifestations of leadership such as vision, innovation, and results while its fundamental essence is coming from inside. It comes from

\footnotetext{
${ }^{*}$ Corresponding author: Shirzad Mansouri

E-mail: shirzad24@gmail.com
}

The Author(s). Published by TAF Publishing. This is an Open Access article distributed under a Creative Commons AttributionNonCommercialNoDerivatives 4.0 International License 
deeper reality within us. It emanates from our values, principles, life experience and essence (Cashman, 2012). As it was discussed in his book, Cashman believed leadership is a process as well as an intimate expression of who we are. It has also been emphasized that we have the tendency to view leadership as an external event. To be more precise, Leadership comes from deeper reality within a person. It emanates from the person's value, principles, life experience and essence (Cashman, 2012). In simple terms leadership is a whole person in action. Therefore, in an organization it is contributing to connecting people to their core values and core talent to their clients as well as their lives. Good, authentic and valued leadership comes from inside of a leader who knows himself. The word "Self" is the core term in all existing literature. Therefore, it requires brief review to strengthen the foundation of any types of leadership in various types of organizations.

\section{The Role of Self in Leader and Leadership Development}

Developing as a leader in general is a well-recognized theme among educational leaders as well as business leaders. The requirements mentioned by various educational leader developers emphasize developing oneself by acquiring cognitive and personal strategies or skill development in creativity, goal setting, negotiating and time management in order to become a role model for his or her students. The self is, however, a loose concept for leaders while it is the stepping stone for self-development. It is the leader's own development process which is central where it is leader's self-awareness, organizational environment mastery, connecting with ideals, and mind and heart felt activities that constitute leader's leadership development. Various studies argue that more self-control, self-estimate and self-confidence are the results of self-awareness and self-development. As an evidence, research found that there is a correlation between the way in which we perform our roles in our organization and the principles to which we personally ascribe (Rue, 2001). Such a leader has gone through a process which is called leader development in which the attention is on intrapersonal capabilities such as self-awareness, self-regulation, and selfmotivation. In real practical context, however, these capabilities are essential to be integrative side by side. If such requirements are met, the leader needs to take leadership development whose emphasis is on interpersonal capabilities such as social awareness and social skills. Thus, in social context, a leader needs to interact with other people and the environment in which he is working.

The base for leader development is the integration of cognitive, socioemotional and behavioral skills (Degeling and Adrian, 2004). These qualities are strengthened by attributes such a self-awareness, trust, practical, social, and general intelligence needed for leadership. Goleman (2002), in research with more than 200 large global companies, concluded that traditional qualities associated with leadership are insufficient. The traditional qualities emphasized that IQ would be the main quality which is necessary for leadership whereas Goleman (2002) introduced EQ as one of the essential qualities of a leader. The EQ theory postulates that IQ, known as conventional intelligence, is too narrow; that there are wider areas of Emotional Intelligence which comes from competence models. These competencies determine how we manage ourselves known as personal competence in Goleman's terms as well as how we handle our relationships with others known as social competence. Success needs more 
than IQ which has tended to ignore essential behavioral and character elements. Popper and Raanan (1993) also argued that the development of self-efficacy and awareness of others are taken into consideration by leadership development. Those who have higher social and personal competences have higher degree of self-awareness, and they have more tendency towards selfdevelopment. These people are less ego-centric and have more care for others and more dominance over themselves and have more consistent emotions and are less defensive as Howard and Douglas (1988) stated. Leaders with high EQ pay more attention to how they control themselves and their relationships (Goleman et al., 2002). Other scholars such as Kouzes and Posner (2008) claimed that concepts such as self-confidence in leadership reflect having more probability to try difficult leadership tasks. The concept of self-confidence in leadership makes a distinction between effective leadership and that of ineffective one in difficult situations. Some more scholars such as Kets de Vries (2007) also see it as essential quality for charismatic leadership.

Karp (2013) believed that self is a vague concept in practical leadership though the concept of self is much discussed in various researches on leadership. Tabrizi and Michael (2013) believe that from the moment we are born we have to face and experience various events which associate memories into a story-the story of who we are. These memories, events and experiences made a choice and reflect a story about who I am. The story of our past is so strong that we hear that I believe my past has made me who I am today. This linkage between the past and who I am is a foolish concept which contains the essence of true self when we express subjective narrative we repeat over and over in our mind (Tabrizi and Michael, 2013). The Fish tank metaphor as these authors mentioned is reflecting the true trend of life and it seems essential to clear out the fish tank which is tarnished with negative thoughts. The main point regarding our true self is not how we look in appearance or what we have in our thoughts. It is emphasized that lack of control of our thoughts is not essentially bad; it is an indication of we are not our thoughts. It seems difficult to learn that there is a distinction between our thoughts and what we know as our true self. This realization is known as awareness. This is also true that our emotions also are not what we are though they may affect our behavior but it is not a part of our true core self. In fact, we are not the emotion we experience at any given time. In simple terms if we bring it together we are not the function of the human ego. The ego is defined by Tolle (2005) as the blue print for dysfunction that every human being carries within. It was also proved that our ego attach themselves to external, peripheral or impermanent things shown as "I" (Tolle, 2005). Consequently, it is the initial step if you are honest with yourself. Therefore, Knowing is the first step in which awareness has a crucial role. More precisely, knowing starts by exploring the true "Self".

\section{Inside-Out Effect: Transformation from True Self}

True self is the root for a successful and sustainable futuristic leadership. It will be revealed through a transformational framework known as inside-out effect following KNOW-BE-LEAD trend. The first part of such trend focuses on KNOW which reveals who I am and how the authentic "I" will lead others. Such a framework helps an individual experience the Inside-Out Effect which affects his performance. To clarify the concept, positive psychology as well as 
neuroscience researches (Soosalu and Marwin, 2012) have conducted great numbers of research to improve any individual's performance. As a researcher on motivational psychology at Stanford, Dweck (2006) introduced the power of "Growth Mindset". Based on the findings in developmental psychology, Dweck (2006) classified individuals into two groups: those who have growth mindset and those who enjoy fixed mindset. The growth mindset individuals are more open to challenges and show more resistance while facing hurdles and try to learn more from their failures and see their attempts as the route to dominant mastery. On the other side of this coin, individuals who have fixed mindset believe their abilities are static and inner. These individuals avoid facing challenges and submit to difficulties and neglect feedbacks which are negative but useful. Cashman (2012) also emphasized on personal mastery and believed that each individual is being called to lead by making connections among life experiences, values and talents under certain conditions. This reflects individual's capability to rise to the life challenges based on the person's understanding of his gifts. These connections would lead to a meaningful context. The integration of the values and strengths as Jung (1993) explained is "growth toward wholeness". In his book, The Fifth Discipline, Senge (1994) also believed that individuals who have dominant personal mastery have awareness of their ignorance, their incompetence, their growths and strengths and selfconfident. Besides, the Inside-out Effect transformation emphasized on the role of brain in knowing more inner-self for moving to Be and leading others. Tabrizi and Michael (2013) also made a distinction between rational brain functions and those of intuitive brain to explore true self. The rational brain concentrates on concrete aspects of the issues in a mechanical and analytical way to categorize them for interpretations and order creation from known to unknown. The point is that rational brain fails to function in negativity and fear. It takes a careful and anxious awareness. On the other side, the intuitive brain has tendency towards peace, hope, creative thinking, and curiosity. It tries to make a connection between irrelevant points to find a chance to find solutions in every situation. The point is that mostly human has tendency to rational brain to solve his problems but fails to achieve real happiness. Cooper (2000) also introduced three brains as the result of neuroscience discovery in which the reasoning brain or brain in head influenced human behavior whenever he has new experiences. The daily contact with life creates a kind of emotional state which reminds us of feeling butterflies in stomach depending on how an individual has been trained to rely on his head alone, he might not be able to notice it. The scientific discoveries proved that the human heart develops prior to the nerve system and the brain in head. Every single heart beat in body is another signal of whole body communication which is known as a wave which moves through the arteries faster than the flow of blood. Such a signal is a language of communication internally as the wave pattern changes with heart rhythm. In the brain head there is a part known as medulla which is connected to reticular activating system (RAS). This connects nerves to brain and human spinal cord. It functions as warning system which warns against dangers and creates anxiety and defense in human. RAS is responsible for negative interpretations of events and things around human. It conveys negative threats to the brain to avoid people or follow a hidden agenda to protect a person in a relationship for integrity, social status, and reputation. Soosalu and Marvin 
(2012) went further to believe that the new form of leadership is not about a specific style of leadership, rather it is about the leaders themselves and their potentials to get into new levels of consciousness and wisdom while making decisions. It was believed that such a form of leadership is more sustainable and wise because it requires the leader himself to be more authentic by connecting deeply with his inside for more reliable connection with others and his community he is in touch with. In other words, a wise leader will lead authentically if he has integrated across the three brains of head, heart and gut. This integration of brains will contribute to better decision making. The integration of three brains generates a truly adaptive leadership.

The tool which can help an individual to have better exploration of himself is beginning to use SEE (Tabrizi and Michael, 2013). SEE is a model with three parts which will drive a person towards defining himself and his calling. It creates a sweet spot which is the result of a person's Strengths, things which Evoke and the factors which make a person Elated (SEE) overlap. This means there is such an overlap with its sweet spot that can give a person immediate joy accompanied with a sustained purpose and in consequence its combination with the true self has a recipe for the calling. As the back bone of the selfexploration, SEE model starts with extensive and frequent introspection and comes to an end with the recognition of fundamental nature of a person's calling.

There are several other techniques introduced for better knowing of self by Tabrizi and Michael (2013). The first one is the Enneagram which is a geometric figure illustrating nine fundamental types of personality. It was used to determine the type of personality which is related to other eight types. The Riso-Hudson Quest is another tool which has two parts; each part includes three paragraph descriptions. The reader, after reading all, should rank the paragraphs from three to one in the sequence which shows reader's actual behavior. Besides, there is another personality diagnostic tool which is known as Myers-Briggs (MBTI). This tool helps individuals to discover some of the person's core perceptions and decision-making tendencies. The other tool is Peaks and Valleys which is a technique to think about the best and the worst times known as Peaks and Valleys in individul's life upto this point. Journaling also was introduced as another tool as well as Meditation and Mindfulness which are honest exploring of the question Who am I? More than these tools, Johari Window created by Joseph Luft and Harry Ingham reflects the selfawareness that is achieved through authentic feedback and honest talk with others.

\section{Envisioning Self Towards Core Values}

The main step after knowing the true self is when every individual can learn how to define his vision and envision himself based on the core values for which he stands. As Tabrizi and Michael (2013) put it, it is the transition from selfdiscovery to self-commitment or in the precise terms transition from Knowing to Being. This clarifies that every individual can achieve the Inside-Out Effect when he is living his life professionally and personally in alignment with true self. It will be possible if he can discover his core values and then lives his life in direction of such values to achieve his goal by diminishing his friction and optimizing his inner energy around what matters to him most with a sense of 
fulfillment to get his purpose. This will bring about change in his life. This change when starts with changing him from inside will lead to his authenticity in leading others.

\section{Applicable Domains of Self}

It used to be a common idea among organizational leaders and leaders developers that a good decision is coming from a person who has cognitive intelligence and he will be the one whose decisions can bring success to the company, therefore, learning organizations believed that if they can assemble all the relevant information and analyze it based on logic, it will end up with an effective decision. It means how well the leader can use his head. Later, Goleman, et al. (2002) stated that IQ cannot be the only type of feature for a successful leader. The cognitively successful leader has just $20 \%$ chance of success and the rest is dependent on how well he can emotionally handle himself and his relationship with others.

The role of EQ as stated by Goleman et al. (2002) is inevitable at this stage because it links personal competence to social competence. The personal competence includes self-awareness and self-management. To be more precise, Goleman's Emotional Intelligence has five elements such as self-awareness, selfregulation, motivation, empathy and social skills. Learning more about true self would be dedicated to this element where a person knows and cultivates strong sense of who he is and how he feels under different circumstances while he is living. After being well aware of his own strengths and emotions, self-regulation will reflect more mastery over such strengths and emotions by maintaining perspective through conscious choice making to stay away from the ego. The motivation for fruitful life starts with passionate choice of core values by heading in the path of meaningful life. This stage of life will achieve the goal of leading with authenticity by having empathy for others when the Inside competencies push to be more compassionate towards others. Such a passionate care and emotion towards others will empower the inner self to learn more about others and how to skillfully contribute to their well-being. The last element of EQ underlines the requirements needed for empowering others. The great change in a person emanates from the passion for helping others and creates a sense of being responsible for others.

It is the self which regulates the inner condition of the individual (leader) on which the success of his practice (leadership) relies as Scharmer (2007) argued. The individual's self is risen in response to and formed by daily demands in person's life and his continuous interaction within his organization or his school. In a profound study Chamine (2012) introduced Positive Intelligence (PQ) which is groundbreaking practice of stress-free performance. PQ was developed over long coaching period of many companies' leaders as well as their teams by Chamine (2012) at Stanford university. The highly effective stress-free method of PQ helps individuals develop their mastery over their minds to reach their potentials. According to his findings, every individual's mind sometimes works for and sometimes is against him. The tug of war exists between the negative saboteurs which sabotage his health and success and his sage which is a serving mind that positively supports his success and joys. In consequence, Positive Intelligence leads you find the way to the sage for better life. The PQ functions inside an individual's minds is the third domain of self 
when applied with an individual IQ and his affective side of personality known as EQ, can create a leader who can bring change to the organization while he makes decision.

Applicable domains

Source: Mansouri and Mhunpiew (2015)

FIGURE 1. Applicable domains of self

\section{CONCEPTUAL FRAMEWORK OF INSIDE-OUT EFFECT}

Authentic leaders do not see themselves as victims of their circumstances. They do not lament their lack of formal authority, and they do not wait for others to come to their rescue. They accept responsibility for their contribution to the situation, and they are committed to making a positive difference.

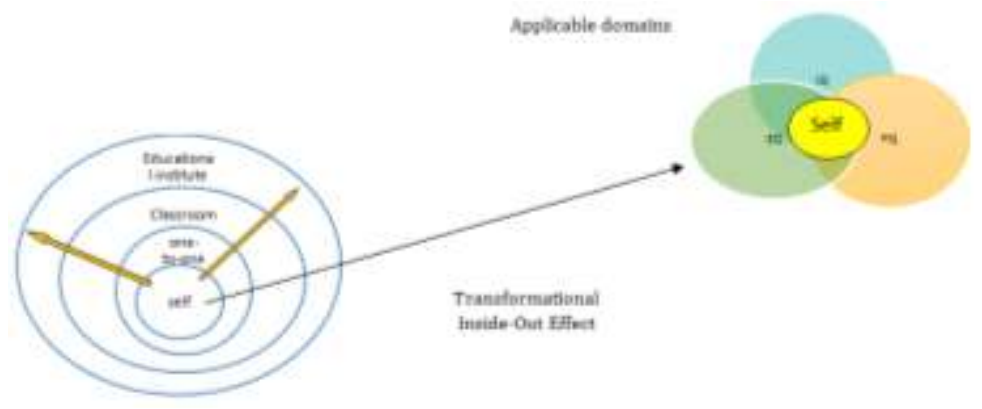

Source: Mansouri and Mhunpiew (2015)

FIGURE 2. The conceptual framework of the study

We think of self and leadership connection as 5 concentric circles that build upon one another (See Figure 2). It starts within through becoming consciously aware of ourselves, who we are, what we stand for, what we care about more than the next raise, promotion or the approval of those around us. Awareness enables choice, and is at the core of self-leadership. Once we can lead ourselves then we can reach out to lead others one-on-one. As mentioned earlier, the only way we have to lead other people is through communication, both by talking and listening. Once we are capable of leading one person through effective communication we can tackle the more complex social dynamics involved in leading a team - keeping everyone rowing in the same direction. Beyond team leadership lays the challenge of leading a cross-functional organization, which is 
more like being the captain of a super-tanker. You can't just grab the wheel and make a quick turn, and it can take a very long time to get your direction to turn into changes where the ship is headed and how quickly it is done.

\section{Self in Inside-Out-Effect Practice: Strategies in Real Context of Teaching and Learning}

Various studies (Houghton and Neck, 2002; Ricketts, et al. 2012) suggested different strategies which emanated from self-leadership, a process whereby individuals try to use self-awareness, self-management, self-motivation and self-direction to behave in a manner necessary for hilarious outcomes reflected in their workplace i.e. classroom. Ricett, et al. (2012) classified self-leadership strategies into three overall dimensions of behavior-focused, natural reward, and constructive thought pattern strategies.

The first category is behavior-based strategies which mostly focus on selfawareness in which individuals try to manage their behaviors. The behaviorbased strategies have five sub-scales which are self-observation, self-goal setting, self-reward, self-punishment, and self-cueing. Self-observation scale is when an individual observes his own behavior which would end up in better realization of when and why he or she behaves like that. This will also lead to a capability to change or leave certain behaviors. Self-goal setting refers to the time when a person sets challenging goals particular to himself that show a strong will and motivating impact on his performance. Self-reward is when an individual uses something as reward either tangible or abstract to encourage favorable behaviors and goal achievements. Self-punishment is a scale in which an individual tries to control and form favorable behaviors through effective constructive criticism which will be more influential than punishment. Selfcueing refers to application and practice of such favorable behaviors before real time and actual performance which will prevent certain expensive drawbacks (Houghton and Neck, 2002).

Natural reward strategies concentrate more on the happy dimension of activity. The individual focuses on thoughts on the intrinsic rewards of such activity or motivation formed for the performance of a particular task. This sense of self-achievement and reward enhances the competence and increases a feeling of self-control and purpose. Houghton and Neck (2002) believed that activities and tasks in classroom for instance create more joy and favorable work environment and lead to more job feature appreciation which leads to the person's higher level of performance.

The last dimension of self-leadership in this regard is constructive thought pattern strategies which are the construction and sustaining ground for creating thought patterns which inspire positive thinking as Norris (2008) introduced it. In such dimension an individual visualizes his successful favorable behavior, self-talk and his evaluation of his own performance and beliefs. At this dimension an individual goes through self-analysis in which he identifies and discards negative thoughts and replaces them with more positive, rewarding reinforced thoughts. In the same manner, self-talk would be replaced by sage which is a serving mind that positively supports his success and joys (Chamine, 2012).

All the above mentioned strategies pave the ground for a rationale that how an individual perceives himself in his leadership role. These strategies reflect a 
clear image of how a person can see himself intra-personally and how to apply them as the foundation of his personal successful performance and bridge the gap for transferring the good spirit of goodness to others.

\section{CONCLUSION AND RECOMMENDATIONS}

The foundation and base of successful leadership in any learning organization whether in business or education organizations is self. Therefore, it is important for any leader to comprehend the self in relation to the real act of leading his followers. True self is the core and the essence of the action of leadership. The qualities of self is the determination of the leader's understanding of himself as a true human. The leader therefore is bound to cultivate understanding of self for performing his role as a leader. This cultivation will lead to transformational Inside-Out Effect which is the well-ground foundation for a leader how to know himself and understand his own capabilities to have a growth mid-set for being what you are. These capabilities of leaders will be explored through psychological development which focuses on cognitive domain or IQ then shifted to affective domain of human personality. The emotional side of human proved would be more effective than IQ (Goleman, et al., 2002). EQ underlines the requirements needed for empowering others. In addition to this, PQ reflects the existing tug of war between the negative saboteurs which sabotage his health and success and his sage as a serving mind that positively supports his success and joys. The combination of three domains of personality inside a person needs to be revealed and transformed into the outer layer of human being. Such a transformation is Inside-Out Effect of self and is a process whereby individuals try to use self-awareness, self-management, selfmotivation and self-direction to behave in a manner necessary for successful outcomes. This transformation is reflected through strategies for real world of learning organizations such as a classroom. This self-analysis will lead to the elimination of negative thoughts and behaviors and replace them by more positive thoughts and behaviors as well as more sage in self-talk as a serving intuitive mind for successful and positive outcome. All in all, the application of these strategies in the real context of learning organizations would be the rationale for the necessity of knowing ourselves to be more powerful to bridge the gap between what we are and how we can empower others i.e. our students and what we can do for our organizations.

\section{References}

Chamine, Shirzad. 2012. Positive intelligence. Austin, TX: Greenleaf Book Group.

Cooper, Robert K. 2000. A new neuroscience of leadership: Bringing out more of the best in people. Strategy \& Leadership 28, no. 6: 11-15. D0I: 10.1108/10878570010694365

Degeling, Pieter, and Adrian Carr. 2004. Leadership for the systematization of health care: The unaddressed issue in health care reform. Journal of Health Organization and Management 18, no. 6: 399-414. D0I: $10.1108 / 14777260410569975$

Dweck, Carol. 2006. Mindset: The new psychology of success. New York, NY: Ballantine Books.

Norris, Sharon E. 2008. An examination of self-leadership. Emerging Leadership Journeys 1, no. 2: 43-61.

Goleman, Daniel, Richard E. Boyatzis, and Annie McKee. 2002. Primal leadership. Realizing the power of emotional intelligence. Boston, MA. Harvard Business School Press. 
Houghton, Jeffery D., and Christopher P. Neck. 2002. The revised self-leadership questionnaire. The Journal of Managerial Psychology 17, no. 8: 672-691. DOI: 10.1108/02683940210450484

Howard, Ann, and Douglas W. Bray. 1988. Managerial lives in transition: Advancing age and changing times. Adult development and aging. New York, NY: Guilford Press.

Jung, Carl, G. 1957. The undiscovered self (Present and Future). New York, NY; Bollingen.

Karp, Tom. 2013. Developing oneself as a leader. Journal of Management Development 32, 1: 127-140. DoI: 10.1108/02621711311287080

Kets De Vries, Manfred. 2007. Executive complexes. Organizational Dynamics, 36, no. 4: 377-91. D0I: 10.1016/j.orgdyn.2007.06.004

Kouzes James M., and Barry Z. Posner. 2008. The leadership challenge, 3rd ed. San New York, NY: Doubleday Currency.

Peterson, C. and Seligman, M.E.P. (2004). Character strengths and virtues. A handbook and classification. Oxford University Press, Oxford.

Popper, Micha, and Raanan Lipshitz. 1993. Putting leadership theory to work: a conceptual framework for theory-based leadership development. Leadership \& Organization Development Journal 14, no. 7: 23-27. DoI: 10.1108/01437739310047001

Ricketts, Kristina G., Hannah S. Carter, Nick T. Place, and Teresa McCoy. 2012. A look inside: Self-leadership perceptions of extension educators. Journal of Extension 50, no. 5: 1-15.

Rue, Bob. 2001. Values-based leadership: determining our personal values. Behavioral Science. URL: http://www.au.af.mil/au/awc/awcgate/dau/rue-ja.pdf (accessed June 14, 2016).

Scharmer, C. Otto. 2007. Theory U: leading from the future as it emerges. Cambridge, MA: SoL: Society for Organizational Learning.

Senge, Peter M. 1994. The fifth discipline: The art and practice of the learning organization.

Soosalu, Grant, and Marvin Oka. 2012. Neuroscience and the three brains of leadership. mBIT International Pty. Ltd.

Tabrizi, Behnam, and Michael Terrell. 2013. The inside-out-effect: A practical guide to transformational leadership. California, CA: Evolve Publishing Inc.

Tolle, Eckhart. 2005. A new earth: Awakening to your life's purpose. New York, NY: Penguin Group.

- This article does not have any appendix. - 